\title{
O Processo de inovação nas biotecnologias: a passagem do objeto de conhecimento ao objeto industrial
}

José Wladimir Freitas da Fonseca*

$\mathrm{Na}$ última década, o desenvolvimento econômico apoiado na área de biotecnologia assistiu a uma invasão repentina e violenta dos "organismos geneticamente modificados" na esfera do consumo e o surgimento de novas tecnologias no quadro do ser vivo que supõem um duplo domínio: de um lado, a montante, no domínio do conhecimento do ser vivo que resulta de uma pesquisa fundamental; de outro, no domínio da fabricação de produtos suscetíveis de responder a uma demanda social, o que supõe a existência, a jusante, de mercados necessários ao escoamento de mercadorias de novos procedimentos.

Encontramo-nos, portanto, em um processo de inovação, conforme o duplo sentido dão Cohendet e Gaffard (1990, p. 935): de um lado, pois "a inovação não é nada mais do que o processo pelo qual tecnologias, previamente definidas fora da esfera da economia, são adaptadas e difundidas no tecido econômico pelas empresas"; de outro, pois "se reconhece que a constituição das tecnologias é um fenômeno essencialmente econômico de tal forma que a inovação é o processo pelo qual elas são criadas". Todavia, isso supõe que as empresas de biotecnologias se inscrevem nas redes científicas nas quais os laboratórios públicos de pesquisa (na maior parte dos casos) ocupam um lugar determinante; ademais, o desenvolvimento do conhecimento do ser vivo se codifica mais do que ele se tecniciza e se finaliza, o que revela a importância dos processos de industrialização.

No domínio das biotecnologias, talvez mais do que em outros domínios, se coloca o problema, o qual chama-se mais geralmente de transferências de tecnologias entre os laboratórios, onde se desenvolve a engenharia de procedimentos no domínio do ser vivo (engenharia genética, enzimática, etc...), e o setor industrial no qual os procedimentos são destinados a fim de permitir uma melhor valorização. Isso não significa, no entanto, que existe uma relação linear entre estes dois atores. Existe, com efeito, certa distância entre o tubo de ensaio, no qual o pesquisador desenvolveu um objeto técnico, e a empresa que vai tratar a informação contida neste tubo de ensaio para fins industriais e com destino ao mercado. Assim, nosso objetivo é seguir, através de exemplos concretos, o processo de transferência que vai do laboratório ao mercado.

\footnotetext{
* Doutor pela Universidade de Toulouse I (França). Professor do Departamento de Economia da Universidade Federal do Paraná (UFPR). Endereço eletrônico: wladi@,ufpr.br
} 
Nossa abordagem da técnica se faz, portanto, a montante, no quadro de uma abordagem empírica do processo de transferência de tecnologia entre um laboratório de pesquisa que acabou de finalizar um novo objeto técnico e uma empresa que deseja se apropriar deste novo objeto com o objetivo de uma valorização pela produção e comercialização. Nesta perspectiva, a técnica é, portanto, definida como uma seqüência coerente de informações que um utilizador coloca em movimento a fim de transformar a matéria, organizada a sua participação neste movimento e nesta transformação, e que isso se passe tanto no nível da oficina como nos níveis da empresa e do setor. Uma parte importante desta informação é, portanto, detida por esta técnica, mas também pelo conjunto de seus idealizadores e de seus utilizadores (engenheiros e operários).

A partir de então, transferir uma técnica significa passar suas informações, no seu conjunto, de um agente econômico a outro. Neste momento já aparecem as dificuldades operatórias que implicam tal movimento e, assim, propomos abordar aqui este problema de forma bem experimental através de exemplos concretos que relacionam um sistema de formação, de instituições públicas de pesquisa e um sistema de recepção de empresas que estão em vias de criação ou de criação recente.

Nossa contribuição tem, portanto, um duplo objetivo: de uma parte, mostrar como se produz a lógica de transferência de um laboratório de pesquisa que desenvolve os conhecimentos e as técnicas para as firmas industriais que as colocam economicamente em valor (no sentido de valorização do objeto); e de outra parte, liberar as bases de uma teoria da inovação que, contrariamente às abordagens standart, não confere à técnica um papel determinante.

\section{As plataformas tecnólogicas}

\section{$1.1 \mathrm{O}$ quadro institucional da abordagem monográfica}

A instituição universitária que nos interessa aqui, sob uma forma monográfica, a fim de descrever o movimento específico que adota a transferência de tecnologia, é constituída por um conjunto homogêneo, fortemente integrado e que aparece sob a forma de duas entidades distintas: o Departamento de Engenharia Bioquimica e Alimentar do Instituto Nacional de Ciências Aplicadas de Toulouse (INSA), na França, que tem por vocação formar engenheiros em bio-indústria, e o Centro de Bio-engenharia Gilbert Durand, centro de pesquisa dividido em várias unidades e articulado em um Centro Regional de Inovação e de Transferência de Tecnologia (CRIT'T). 
O domínio da pesquisa do Departamento de Engenharia Bioquimica e Alimentar diz respeito às biotecnologias (ou bio-engenharias) e, a este título realiza uma junção entre as ciências do ser vivo e as bio-indústrias, mais particularmente no domínio da saúde, da química fina, da agroindústria e das tecnologias do meio ambiente.

\subsection{As condições da transferência de tecnologia: do laboratório à indústria}

No caso das biotecnologias, encontramo-nos em um setor onde as parcerias econômicas são mais aptas a integrar uma tal estratégia em matéria de inovação na medida em que a concorrência entre os atores industriais para o domínio do ser vivo parece ser mais estimulante do que em outro domínio. Ademais, trata-se de um setor jovem e que está sendo rapidamente internacionalizado, quer dizer, mais aberto e em forte progressão. Por exemplo, no domínio da saúde, as apostas estão sendo particularmente importantes e as perspectivas de desenvolvimento consideráveis.

Se isso é particularmente verdadeiro no domínio da saúde, o mesmo ocorre no domínio da agroquímica e, mais geralmente, para tudo que está relacionado ao agrofornecimento, sendo o conjunto destas produções fundadas sobre a inovação e, muitas vezes, a única razão de ser de certas indústrias. Em outro, as características deste setor têm uma outra conseqüência: com o fato da sua dependência relativa dos laboratórios de pesquisa, pois ele não pode passar distante da inovação (de metodologia, de novas técnicas ou de um melhor conhecimento do ser vivo), este setor é obrigado, cada vez mais, a se apoiar nos laboratórios de pesquisa mais do que ocorre em outros setores. Isto é a razão pela qual, pese as hesitações bem compreensíveis dos pesquisadores, nós encontramos neste setor, muito cedo, as colaborações fortes entre o setor privado e pesquisa pública. Mais ainda, é certamente no domínio das biotecnologias que a pesquisa pública foi mais longe nas parcerias com os industriais e certos pesquisadores tornando-se, eles mesmos, industriais.

Através de uma constatação, uma distinção se impõe no que concerne às condições nas quais se desencadeiam as transferências de tecnologia. Com efeito, as modalidades de transferência serão diferentes conforme o caso que configura e no qual nós nos encontramos do ponto de vista do industrial. Duas situações se apresentam: de uma parte, a transferência que se efetua no quadro de uma atividade já existente; de outra parte, trata-se da criação de 
uma empresa que desenvolveu uma nova tecnologia e, através da propriedade da patente, deseja explorá-la. Trata-se mais freqüentemente da criação da start-up ${ }^{20}$.

\subsection{Da construção dos conhecimentos à industrialização: as linhas de uma} valorização

A situação de transferência que acabamos de evocar só pode realmente ter sentido e dar lugar a uma interpretação teórica, na medida em que ela se encaminha para um exemplo concreto no qual podemos investir a fim de interpretá-lo. Nosso objetivo vai, portanto, consistir em apresentar a anatomia de um programa de pesquisa que opera, ao mesmo tempo, os dispositivos de pesquisa que se exprimem nos laboratórios públicos de pesquisa, mas também, os processos de transferência através das relações que se constroem a montante (o laboratório ou a criação dos conhecimentos) para a jusante (a industrialização dos conhecimentos). Tomamos o caso do Centro G. Durand onde acompanhamos suas experiências trazendo nossa atenção sobre o trabalho das equipes.

\subsubsection{O caso dos Fluidos Supercríticos}

A história do programa de pesquisa no domínio dos Fluidos Supercríticos pode ser analisado em duas etapas. A primeira etapa consistia em determinar em qual medida as enzimas podiam funcionar nos fluidos supercríticos: a idéia era ver a possibilidade de fazer funcionar as enzimas nesse meio. A partir desse trabalho de pesquisa fundamental, a equipe acumulou um bom conhecimento neste domínio, permitindo a publicação de uma tese de doutorado e vários artigos em revistas internacionais. Em que pese todo um conhecimento adquirido, durante esta etapa, nenhuma aplicação direta foi considerada. Foi necessário esperar até 1992, quando a empresa Bioland, do setor medicinal, vai propor ao laboratório Gilbert Durand um estudo sobre a aplicação dos fluidos supercríticos no caso de limpeza e purificação de ossos: o princípio é limpar o melhor possível os ossos de vaca que serão utilizados como próteses humanas. Todavia, tratava-se de uma problemática sensivelmente diferente daquela ligada a idéia de partida e, desta forma, foi necessário adquirir, em conseqüência, um conhecimento-técnico mais específico e, portanto, assegurar o domínio deste novo meio, quer dizer, a aplicação dos fluidos supercríticos para a limpeza de osso.

20 As start-ups são pequenas empresas especializadas em produtos biotecnologicos criadas à partir de um pesquisador ou grupo de pesquisadores. As start-ups são, sobretudo na Europa, uma interface entre as universidades e as indústrias, cujo objetivo, a montante do mercado, é o de transformar uma boa idéia ou um bom conceito em um bom produto ou serviço. (Hamdouch e Depret; 2001). 
Durante esta etapa, e em paralelo, um programa europeu estimulou a continuar os estudos fundamentais sobre os fluidos supercríticos, as enzimas e os estudos de conexão-reação-separação em colaboração com várias universidades européias.

A segunda etapa era responder a uma demanda industrial e em paralelo aos estudos fundamentais. Durante este período, os resultados foram os seguintes: duas teses publicadas, oito publicações científicas em revistas internacionais, das quais, sete são sobre conexão-reaçãoseparação e uma sobre a parte de aplicação. Uma patente sobre a limpeza de osso através dos fluidos supercríticos foi depositada e constitui um ponto de resultado completo do trabalho ao mesmo tempo que um ponto de partida industrial.

\section{Do objeto de conhecimento ao objeto industrial: a importância do objeto} técnico

O domínio destes novos procedimentos enzimáticos necessita de um trabalho pluridisciplinar implicando a enzimologia, a catálise heterogênea, a engenharia dos reatores, e a termodinâmica. Modificar o sentido da reação da hidrólise para a síntese passa pela análise e a compreensão da termodinâmica. Nestes meios não convencionais, a noção de concentração deve ser substituída pela noção menos natural da atividade termodinâmica. Esta é uma imagem da disponibilidade de uma molécula num meio determinado.

Para compreender a passagem do objeto de conhecimento ao objeto industrial é preciso, antes de tudo, identificar o primeiro nível, o nível das ciências. A este nível, mostra dois objetos de conhecimento: de uma parte os estudos que foram feitos sobre as enzimas (neste caso, a equipe de pesquisa trabalhou sobre as enzimas para compreender suas propriedades e fazer os três tipos de reações descritas), e de outra parte, os estudos sobre a termodinâmica a partir da engenharia química e com a utilização das ferramentas termodinâmicas que permitiram melhor compreender e modelar as reações enzimáticas nos meios não convencionais.

As enzimas, de maneira clássica, funcionam na água. As enzimas são moléculas protéicas capazes de acelerar intensamente determinadas reações químicas, tanto no sentido da síntese, como no da degradação. São, portanto, catalisadores biológicos. Todavia, cada enzima tem uma reação catalítica específica, por exemplo: uma molécula A-B em presença de uma enzima vai produzir uma molécula $A$ mais uma molécula $B(A-B \rightarrow$ Enzima $\rightarrow A+B)$, que é uma reação clássica. Todavia, a equipe começou a experimentar reações inversas com a mesma enzima criando uma ligação entre as moléculas $(A+B \rightarrow$ Enzima $\rightarrow A-B)$. Para criar 
esta ligação, é preciso retirar a água na medida em que a mesma impede esta reação. Para isso, a equipe pesquisou outros meios específicos. A primeira experiência foi feita através de solventes orgânicos. Todavia estes solventes, em geral, são tóxicos, inflamáveis e perigosos. Para isso, a equipe pesquisou um outro meio capaz de fazer funcionar as enzimas. Foi o caso do dióxido de carbono $\left(\mathrm{CO}_{2}\right)$. Mas o $\mathrm{CO}_{2}$ é um gás e as enzimas não funcionam neste caso. Desta forma, através de uma combinação específica entre a temperatura e a pressão, este gás passou a um estado supercrítico. Trata-se de uma mistura, quer dizer, metade gás e metade líquido, que torna possível a reação $(A+B \rightarrow$ Enzima $\rightarrow A-B)$. O segundo nível, o nível técnico, é atingido quando a enzima funciona nos fluidos supercríticos, quer dizer, no $\mathrm{CO}_{2}$ supercrítico. Assim, no início, a enzima e o fluido eram os objetos de conhecimentos e quando estes dois objetos foram capazes de funcionarem juntos, eles tornaram-se os objetos técnicos.

A passagem ao objeto industrial se produziu quando os industriais vieram ao laboratório e apresentaram um problema de limpeza de osso. A partir deste momento, a equipe de cientistas verificou que era possível fazer a limpeza do osso a partir do domínio do funcionamento das enzimas e dos fluidos. É incontestável que a utilização da técnica de processos contínuos de reação e separação com a combinação específica de temperatura e pressão foi fundamental para que o objeto de conhecimento se tornasse um objeto industrial e para que a técnica se tornasse um lugar de passagem obrigatória para a transferência de conhecimento.

\section{Uma interpretação teórica das condições da transferência tecnológica}

No que diz respeito às relações que são mantidas entre as atividades científicas fundamentais e as aplicações inovantes que podemos tirar da produção de bens de equipamentos e/ou de bens de consumo, quer dizer, das relações que se estabelecem entre a ciência e a técnica no processo de mudança técnica, os economistas, na sua grande maioria, estabelecem relações mecânicas entre os dois elementos sem identificar e sem distinguir os processos exatos que se produzem assim como suas especificidades.

A técnica, como prolongamento aplicado da ciência, assegura a continuidade desta de forma natural e lógica, mecânica e linear. A partir de então, o papel e o lugar dos atores respectivos se encontram definidos mecanicamente sem que se tenha muito bem compreendido, conforme quais mecanismos se produz esta distribuição e que ela é a natureza desses processos. E mesmo se esta diferença for percebida como, em parte, artificial, ela afeta 
tendencialmente a pesquisa fundamental conferindo o estatuto de operador no domínio científico, com o caráter aplicado reaparecendo do direito das firmas privadas.

Assim, que a questão da técnica seja considerada como endógena ou exógena nos diferentes modelos que estudam as mudanças que ela implica, não encontramos resposta nem no que diz respeito à natureza das relações que se estabelecem entre ciência e técnica (senão uma relação puramente linear sem grande interesse heurístico) nem no que diz respeito à natureza dos processos que levam em conta a passagem da técnica propriamente dita ao processo de industrialização que decorre.

A compreensão dos mecanismos de transferência que expomos, sob forma concisa, toma uma forma dupla, a saber, a tecnicização dos conhecimentos de uma parte, e a industrialização dos conhecimentos, de outra parte.

\subsection{A tecnicização dos conhecimentos}

Partimos da hipótese de trabalho seguinte: o campo de conhecimentos (ou campo epistêmico) se desenvolveu notadamente na biologia molecular, ao mesmo tempo em que os procedimentos técnicos os quais chamamos de processo de tecnicização com a penetração relativamente importante das técnicas no campo dos conhecimentos, a qual acaba por orientar o campo dos conhecimentos sobre a base dos dados técnicos a partir dos quais ele se constitui. Assim, a ciência moderna ${ }^{21}$, se singulariza a partir de sua origem por uma interação fundamental entre técnica e campo epistemático, a primeira não se superpondo a segunda, mas se fundindo na primeira. Esta relação dialética, portanto não linear, entre ciência e técnica deve ser entendida a dois níveis:

- $\quad$ de uma parte, a máquina torna-se um modelo de referência (principalmente para Descartes) para o conhecimento propriamente dito e o modelo mecânico torna-se a base da construção dos métodos;

- de outra parte, a técnica torna-se um meio de acesso ao conhecimento (por exemplo, o microscópio), com o instrumento desempenhando um papel de intermediário cada vez mais solicitado entre o cientista e o objeto a conhecer.

A este título, a história aparece de forma muito sugestiva e não escapa da instrumentação no estudo do organismo vivo. "O vocabulário da anatomia animal, nas ciências ocidentais, é rica em denominação de órgãos, de víceras, de segmentos ou de regiões do organismo exprimindo

21 Nós chamamos de ciências modernas aquelas que emergem com Descartes e que evidencia a maneira como campo da ciência e o campo da técnica entram em relação; a segunda vindo 'percolar' a primeira. 
metáforas ou analogias tecnológicas. O estudo da formação e da fixação do vocabulário anatômico, de origem grega, hebraica, latina e árabe, revela que a experiência técnica comunica suas normas operatórias à percep̧ça das formas orgânicas” (p.232).

Assim, o conhecimento torna-se, fundamentalmente, ao mesmo tempo técnico, no sentido onde se tecniciza, e científico. Se isto é assim, é porque a ciência implica a integração sucessiva e acumulativa das técnicas que se tornam, portanto, um meio indispensável de acesso ao conhecimento. Mais ainda, no seio deste processo, a técnica, pela importância que ela vem ocupar, chega a orientar as construções epistêmicas.

As ciências modernas se impregnam progressivamente da técnica que as "percola" e se apresentam assim de forma original: as ciências modernas partem assim da ciência grega, em se orientando progressivamente para uma forma tecniciana do pensamento. De maneira que, a técnica orienta progressivamente a ciência para uma lógica de construção que é própria. Assim, nas construções epistêmicas que concernem às ciências do ser vivo os fundamentos experimentais, depois instrumentais, que os caracterizam podem assim ser referenciados. Seguindo este movimento de percolação, a técnica tende progressivamente a se substituir pelos outros suportes do conhecimento. Esta substituição orienta, portanto, o discurso (logos) para tornar-se, no sentido experimental e instrumental, essencialmente técnico.

Com a emergência da biologia molecular, a técnica não se limita mais a fornecer os instrumentos ao experimentador. Objeto de experiência e objeto técnico tendem a se confundir. Esta segunda inversão prolonga a pesquisa para o conhecimento, infinitamente pequeno, da vida e, sobretudo, aplica os novos instrumentos para explorar estes domínios. Os níveis celulares e depois intracelulares, acessíveis à observação visual pelo intermédio do microscópio, encontram um limite nas questões que levantam o conhecimento da vida. Uma vez localizados e descritos os fenômenos de divisão celular e de hereditariedade, por exemplo, nem sempre se conhece os mecanismos bioquímicos que se encontram à origem da transmissão dos caracteres. Da célula ao núcleo, depois, do núcleo aos cromossomos, a abertura do campo do conhecimento vai de igual com o aperfeiçoamento dos meios técnicos e dos instrumentos. O papel e as funções dos cromossomos na mitose e depois na meiose se encontram assim evidenciados pelas técnicas específicas. Estas observações abrem, ao seu turno, o caminho para uma série de questões que, pese as proezas técnicas, escapam definitivamente da observação humana. Para os cromossomos portadores dos fatores hereditários, ainda será preciso determinar os elementos que definem estes fatores assim 
como seus modos de transmissão. O que se subtrai da observação torna-se uma aposta científica. De outro lado, técnicas devem, portanto, ser aplicadas para atingir estes fenômenos.

Em contrapartida, a técnica se nutre igualmente dos conhecimentos que ela vem percolar e, em retorno, se encontra impregnada pelos conhecimentos. Todavia, entre estes dois movimentos há uma diferença bastante nítida: a penetração da técnica na construção dos conhecimentos deixa intacto (bem reduzido) o questionamento, mesmo sendo orientado por ela, que consiste sempre em responder à questão "por quê?". Em retorno, da mesma forma, o impacto dos conhecimentos sobre a técnica não modifica o caráter finalizado, particularizado e puramente operatório da técnica que se aprecia somente pela resposta à questão "como?".

Disto resulta uma conseqüência que é, aos nossos olhos, essencial: todo objeto técnico e instrumental finalizado é potencialmente um bem econômico suscetível de ser produzido e, portanto, industrializado. Assim, as técnicas de seqüenciação do genoma não constituem um meio de elaborar uma resposta aos questionamentos da genética neomendeliana, de identificar a base material do gene mendeliano. Esta deriva e desvenda uma tendência à autonomização da biologia molecular, fenômeno no qual a técnica ao mesmo tempo questiona e responde. Paralelamente, o objeto de conhecimento (a seqüência do ADN) coincide com a produção de proteínas e torna-se, ela mesma, um objeto técnico entre as “mãos" do experimentador, quer dizer, mediador entre o homem e a natureza. Da introdução de uma seqüência de $\mathrm{ADN}$ no cromossomo de uma célula, a fim de fazê-lo sintetizar uma ou várias proteínas, para a modificação de certos caracteres de vegetais ou de animais, a fim de aumentar um potencial de produção, vamos identificar aí a emergência do que se convencionou chamar de engenharia genética.

A biologia molecular, enquanto projeto científico em vias de realização (cuja cartografia e interpretação completa do genoma dos organismos vivos constituiriam o símbolo deste resultado) representa igualmente uma forma de ponto de partida de um projeto tecniciano: a engenharia genética. Mas esta passagem concretiza o prolongamento lógico de um processo histórico que se encaminha à tecnicização dos conhecimentos. A construção epistêmica cede o lugar a esta lógica tecniciana que se inscreve na engenharia genética ao ponto em que o argumento tecniciano torna-se a justificação no programa de pesquisa em biologia molecular: o objeto de conhecimento se funde, assim, no instrumento.

Nestas condições, o caráter técnico-epistêmico e as ciências modernas contêm uma aposta econômica e estratégica do ponto de vista industrial. Para ilustrar nosso propósito, consideramos que o quadro dos conhecimentos do ser vivo e os trabalhos de Mendel sobre a 
hereditariedade à biologia molecular, passando pelas biotecnologias é decisivo para nossa demonstração: nos trabalhos de Buffon até a dupla hélice de Watson e Crick, passando pelo eugenismo (quer dizer a utilização dos conhecimentos para fins particulares de melhorar os caracteres em função de critérios específicos), reencontramos o esquema exposto, as biotecnologias e os desenvolvimentos econômicos aos quais pretendem dar lugar, constituindo uma prova bastante notável.

\subsection{Da tecnicização dos conhecimentos à industrialização}

$\mathrm{O}$ instrumento concretiza o prolongamento do gesto e este prolongamento toma o trabalho como intermediário. Ora, todo trabalho é criação de valor (no sentido econômico do termo) o que confere ao instrumento um lugar eminentemente econômico. A partir do momento em que a fabricação dos instrumentos e, por extensão, das máquinas, se insere num processo de criação de riquezas, a tendência à tecnicização dos conhecimentos deve se acompanhar de sua entrada na esfera econômica.

Ora, se a inserção dos resultados do conhecimento nos circuitos econômicos se revela efetiva, significa que, previamente, estes resultados suportaram uma transformação conduzindo-os a se desviar das propriedades aferentes aos bens econômicos (enquanto produto de consumo ou de procedimento de produção) e tal transformação só pode se realizar por uma tecnicização destes conhecimentos.

Assim, a presença sobre o mercado de sementes geneticamente modificadas prolonga os caracteres técnicos incorporados na semente; este aspecto vem contrariar toda outra consideração (a semente enquanto organismo vivo). Esta tecnicização dos conhecimentos se encontra na origem de uma reaproximação entre os programas das instituições de pesquisa pública e aqueles da pesquisa conduzida no seio das indústrias. Esta convergência e as transferências sempre mais importantes que se operam entre a pesquisa pública e privada representam uma manifestação da passagem da tecncização à industrialização dos conhecimentos.

Um instituto público de pesquisa desenvolve essencialmente os programas industrialmente pouco finalizados e esta finalização se mostra, antes de tudo, do domínio da firma. Em outros termos, nós avançamos a idéia de que existe uma reaproximação progressiva e inexorável entre os temas desenvolvidos pela pesquisa pública e aqueles das firmas industriais. 
A tecnicização dos programas e suas finalizações de um lado, e o desenvolvimento dos conhecimentos industriais cada vez mais elaborados de outro, marcam esta reaproximação tendencial. Mas, este movimento é a conseqüência, unicamente, de um processo mais profundo que se apóia sobre a tecnicização dos conhecimentos desenvolvidos anteriormente. Para evocar simplesmente este fenômeno, diremos que a convergência temática das pesquisas públicas e privadas em biologia se opera em torno de uma lógica tecniciana, mais próxima da vocação industrial do que a missão do serviço público, e esta observação fundam certamente o mal-estar que atravessa atualmente a pesquisa pública e o sentimento de que ela se envolve cada vez mais nas pressões e nos imperativos econômicos.

Assim, a biologia molecular se inscreve no prolongamento de uma tecnicização dos conhecimentos do ser vivo e, a partir de certo nível, esta impregnação pela técnica faz movimentar o objeto de conhecimento no conjunto dos bens econômicos e é deste movimento que vamos tratar.

O movimento de tecnicização dos conhecimentos que se opera a montante em detrimento do domínio científico desencadeia, a jusante, uma forma sempre mais tecnicizada das produções científicas. Assim, para voltar ao nosso exemplo, os técnicos que permitem testar as reações de uma enzima num meio diferente do seu, a fim de determinar as condições desta adaptação, tendem a fazer desta mesma enzima um objeto técnico, quer dizer, um instrumento destinado a um fim particular. A partir de então, a concepção instrumental da técnica coloca o trabalho como o fundamento da atividade técnica, colocando assim a técnica no centro da atividade econômica.

Nestas condições, a tendência a tecnicização crescente que se manifesta na constituição dos conhecimentos, estimula os conhecimentos a se instrumentalizar e, portanto, a se finalizar, quer dizer, a se orientar para suas destinações econômicas sob a forma de mercadoria. A tecnicização dos conhecimentos precede necessariamente a industrialização, e este fenômeno de captura pela indústria se manifesta no seio dos campos de conhecimento que já são fortemente "percolados", impregnados pela técnica. Quando este movimento torna-se efetivo, ele induz e impulsiona uma aceleração que toca, portanto, os ritmos da mudança no seio das unidades de produção.

A aplicação dos recursos públicos e privados cada vez mais importantes no domínio da engenharia genética teve como resultado, a partir da última década, decodificar a seqüenciação do genoma e a transgênese que se tornaram, portanto, as apostas maiores. A este respeito é importante evocar a mobilização dos recursos dados à pesquisa a fim de se 
posicionar sobre o mercado das ciências do ser vivo que se abre, seja no domínio da saúde, no domínio do meio ambiente ou a melhora das espécies animais e vegetais (não sem provocar algumas inquietações por parte dos consumidores que não estão prontos a aceitar tudo dentro desta perspectiva).

Esta mudança significativa do ritmo revela o papel, ao mesmo tempo acumulativo e uniformizador, da técnica que mobiliza, ao nível planetário, todos os programas de seqüenciação do genoma de organismos vivos. Nos desenvolvimentos de tal lógica, no que diz respeito à biologia molecular, a técnica desempenha um papel central na medida em que ela tende a se industrializar e, portanto, a se transformar em engenharia genética.

Da tecnicização dos conhecimentos à industrialização, como instância de transição, se manifesta à dimensão econômica do processo. Se a tecnicização dos conhecimentos modifica primeiro para depois orientar a construção, conforme as modalidades e as pressões que somente as técnicas impõem, a industrialização faz entrar as formas técnicas do conhecimento no domínio comercial que os submete assim à sua própria lógica.

Dois índices significativos conduzem a considerar a industrialização dos conhecimentos como prolongamento contínuo de sua tecnicização. O primeiro repousa sobre as transformações profundas que conhecem as instituições públicas de pesquisa cuja atividade de pesquisa se traduz por uma finalização industrial cada vez mais dos programas de pesquisa, notadamente no que diz respeito à biologia molecular. Nós já havíamos sublinhado a importância que desempenha os genopólos neste domínio, com os laboratórios públicos tornando-se, então, os parceiros mais ou menos voluntários das empresas privadas. As monografias apresentadas na segunda parte se inscrevem nesta lógica, não restando nenhuma dúvida sobre as relações de proximidade entre público e privado, o que não gera problemas em um país onde a importância do setor público é difícil de desmentir. Um segundo índice se exprime através do lugar preponderante que ocupa os conhecimentos universitários nas estratégias de pesquisa e desenvolvimento das firmas. Neste caso, igualmente, o exemplo precedente mostra que no final da cadeia que articula pesquisa e técnica, as firmas ocupam o lugar privilegiado, ou seja, "o lugar onde se colhem os frutos que foram semeados por outros".

\section{Conclusão}

Se nos referimos à literatura econômica tradicional, os processos de transferência de tecnologia e de inovação são simplesmente descritos e raramente explicados. Ademais, a 150 
descrição está a serviço de uma validação ex post dos modelos existentes, que se trata da teoria da agência (Dasgupta e David; 1986), das abordagens neo-institucionalistas (Quéré-Ravix; 1997) ou das abordagens neo-schumpeterianas e evolucionistas (Dosi, Teece-Winter; 1990 \& Nelson; 1991).

Mostramos, nesta contribuição que, sobre a base de uma descrição prévia das estruturas institucionais e a partir do estudo concreto e prático das relações entre atores no processo de transferência e de inovação, é possível construir uma abordagem teórica que leve em conta o conjunto dos elementos constitutivos destes processos. Além disso, com os conceitos de tecnicização e de industrialização dos conhecimentos, agora é possível integrar a técnica como variável explicativa enquanto que os modelos, standart ou outros, são incapazes.

Não somente a técnica não é mais uma variável paradoxalmente incômoda, como desempenha um papel central no processo, no qual ela é constantemente citada: o processo de transferência de tecnologia.

\section{Referências bibliograficas}

AMABLE B., BARRÉ R., BOYER R. (1997). Les systèmes d'innovation à l'heure de la globalisation. Ed. Econômica: Paris.

COHENDET P., GAFFARD J. L. (1990). Encyclopédie économique (sous la direction de Greffe X.). Ed. Econômica: Paris.

FONSECA, J. W. F., MIGNOT J. P. (2001). La construction des relations Recherche-Industrie dans les sciences du vivant: problèmes théoriques et pratiques. Séminaire de Montevideo, 17/19 juillet 2001, 18 pages.

GANGUILHEM G. (1986). Etudes d'Histoire et de Philosophie. Ed. Vrin: Paris.

GIANFALDONI P., GUILHON R. (1990). "Chaînes de compétence et réseaux" In: Revue d'Economie Industrielle, $\mathrm{n}^{\circ}$ 51, p. 98 sq.

HAMDOUCH, A., DEPRET, M. (2001). La nowvelle économie industrielle de la pharmacie. Ed Elsevier.

MIGNOT J. P., PONCET C. (1997). La relation techné-épistémé dans la construction de la biologie moderne. - Colloque "Faut - il créer un privilège sur le vivant?" Montpellier - IAM Septembre

MIGNOT, J. P. (2000). Evolution de la Recherche publique et dynamique industrielle dans le domaine des biotechnologies en Midi-Pyrénées Rapport intermédiaire - 72 pages.

PERRIN J. (1984). Les transferts de technologies. Ed. La Découverte: Paris.

ROQUEPLO P. (1979). La technique comme opérateur social. La revue de l'entreprise 
